\title{
Juventude e Participação: - grêmio estudantil como espaço educativo
}

\author{
Francisco André Silva Martins' \\ Juarez Tarcísio Dayrell'
}

'Universidade Federal de Minas Gerais (UFMG), Belo Horizonte/MG - Brasil

RESUMO - Juventude e Participação: o grêmio estudantil como espaço educativo. $O$ presente trabalho tem como objetivo analisar a participação de jovens no cotidiano escolar através do grêmio estudantil de uma escola publica de Ensino Médio noturno, buscando compreender os possíveis significados e aprendizagens decorrentes desse tipo de participação para os estudantes envolvidos. As principais ferramentas metodológicas foram a observação participante e o desenvolvimento de entrevistas semiestruturadas. A análise dos dados revelou, dentre outros aspectos, que o grêmio se constitui como um importante espaço de socialização para os jovens alunos, com ênfase na aprendizagem da vivencia coletiva, no lidar com os conflitos e no exercício de escolhas, dentre outras.

Palavras-chave: Juventude. Participação. Grêmio Estudantil.

ABSTRACT - Youth and Participation: the student council as educational space. The present study aims to analyze the participation of young people in school life through the student council of a public high school at night, trying to understand the possible meanings and learning resulting from this type of participation for the students involved. The main methodological tools were the participant observation and the development of semi-structured interviews. The analysis of the data showed, among other things, that the guild is an important area of socialization for the young students, with emphasis on learning of collective experience in dealing with the conflicts and in the exercise of choices, among others.

Keywords: Youth. Participation. Student Council.

Educação \& Realidade, Porto Alegre, v. 38, n. 4, p. 1267-1282, out./dez. 2013

1267

Disponível em: <http://www.ufrgs.br/edu_realidade> 
Juventude e Participação

\section{Considerações Iniciais}

O presente trabalho parte dos esforços empreendidos em uma pesquisa de mestrado e tem como objetivo analisar as experiências participativas vividas cotidianamente pelos jovens estudantes pertencentes ao grêmio estudantil de uma escola pública de Ensino Médio e os possíveis aprendizados decorrentes de tal atuação. A escola ${ }^{1}$ em que se desenvolveu o estudo é ligada a uma Fundação Municipal que oferece Ensino Médio Regular e Técnico em um município da região metropolitana de Belo Horizonte. Como procedimento metodológico, foi empreendido um estudo de caso, com uma abordagem qualitativa, tendo como ferramentas metodológicas a observação participante e o desenvolvimento de entrevistas semiestruturadas.

A escola pesquisada está situada em um bairro de periferia que se formou por intermédio da doação de terrenos por parte da prefeitura. É um local que ainda peca pela falta de infraestrutura necessária aos seus habitantes. A escola foi fundada no ano de 2006. A unidade estudada se dedica ao Ensino Médio Regular e à Educação de Jovens e Adultos de Nível Médio. De acordo com a direção da escola, a vinda de uma unidade da Fundação para o bairro se deu mediante mobilização da comunidade junto à prefeitura. Os alunos são moradores do próprio bairro ou de bairros mais próximos. Em sua maioria são trabalhadores que, durante o dia, deslocam-se para o centro da cidade, voltando ao bairro à noite para o estudo e o descanso. A escola não conta com um prédio próprio, funcionando junto a uma escola de Educação Fundamental pertencente à Rede Municipal de Educação. A escola da Rede funciona nos horários matutino, vespertino e noturno. Já a escola pesquisada funciona somente à noite.

Em se tratando da escola há que se destacar alguns aspectos em relação à Fundação a qual ela pertence. A Fundação é uma instituição mantida pela prefeitura, foi criada em 1973, e na época da pesquisa oferecia Ensino Médio Regular e Ensino Técnico nas áreas de saúde, informática, gestão e química industrial. É uma instituição que goza de um enorme prestígio junto a população do município. Na época da pesquisa, contava com 8.530 alunos distribuídos em 17 unidades e tinha um investimento anual de $\mathrm{R} \$ 21$ milhões de reais. Além dos aspectos citados, o acesso se dava mediante concurso público para seleção de alunos, o que denotava um forte caráter simbólico aos estudantes que alcançam uma vaga na instituição.

O grêmio teve seu inicio juntamente com o funcionamento da escola. A chapa pesquisada marcava a atuação da $3^{a}$ gestão. Em relação aos jovens que atuavam no grêmio, dos 10 participantes da direção, nove foram acompanhados e entrevistados, sendo quatro meninas e cinco meninos com idade variando entre os 16 e os 17 anos. No que tange à vida escolar, todos os jovens, sem nenhuma exceção, tiveram suas trajetórias desenvolvidas, exclusivamente, em instituições públicas, sejam elas municipais ou estaduais. Além disso, nenhum deles foi

1268 Educação \& Realidade, Porto Alegre, v. 38, n. 4, p. 1267-1282, out./dez. 2013 Disponível em: <http://www.ufrgs.br/edu_realidade> 
reprovado em toda sua vida estudantil. Dos nove jovens, sete estavam trabalhando ou já tinham trabalhado para ajudar no sustento da casa.

Em relação ao grêmio estudantil optamos por analisar as experiências vividas pelos jovens, a organização da entidade estudantil, as atividades desenvolvidas, seu funcionamento, a relação com os alunos da escola, bem como as relações estabelecidas no interior do próprio grêmio. A presença do pesquisador na escola, inicialmente, causou certa desconfiança, tanto dos adultos quanto dos jovens. O diretor da escola queria entender quais os motivos de se pesquisar um grêmio, bem como quais os motivos de pesquisar aquela escola em particular. Alguns professores chegaram a pensar que aquele estranho poderia ser um observador enviado pela Secretaria de Educação do município. Os jovens do grêmio pensavam que se tratava de alguém inserido pela direção para observar o que eles faziam. De certa maneira havia uma desconfiança generalizada em torno daquele estranho que começava a frequentar a escola cotidianamente.

Como superar essa desconfiança? Esses obstáculos, normais em uma pesquisa dessa natureza, foram transpostos paulatinamente através da postura do pesquisador nas relações cotidianas durante o período da observação, ocorrido entre março e agosto de 2009. O intuito foi ser o mais sincero possível, deixando claro qual o motivo de estar ali, ou seja, uma pesquisa científica, explicando o que seria a pesquisa, com conversas informais no momento do intervalo e na troca de ideias. Além disso, houve também uma aproximação das atividades para além do grêmio, idas ao shopping, encontros na praça do bairro, viagens, cinema.

Significou um movimento de aproximação, com avanços e retrocessos, mas sempre deixando bem claro que se tratava de um trabalho sério e que posteriormente todos teriam acesso. A tentativa foi de demonstrar que não havia nenhuma espionagem e nem mesmo intenção de intervir nas atividades do grêmio. Gradativamente aquele que era o estranho passou a não ser notado ou a não chamar tanta atenção. A aproximação e a confiança dos jovens permitiram a visualização de nuances importantes em torno da atuação e funcionamento do grêmio estudantil.

\section{Organização Desorganizada: práticas e transgressões juvenis}

Inserido na dinâmica escolar, encontra-se o grêmio estudantil, uma instituição que legalmente representa os interesses dos estudantes. Quando se fala em grêmio, logo somos levados a pensar em reuniões marcadas por um calendário pré-estabelecido e com horário prédeterminado, com pauta para assuntos a serem discutidos, ata durante a reunião, sala própria para encontros, discussões e guarda dos documentos em locais apropriados, pré-requisitos básicos ao se tratar de uma entidade convencional que funciona na lógica do adulto.

Educação \& Realidade, Porto Alegre, v. 38, n. 4, p. 1267-1282, out./dez. 2013. 1269 Disponível em: <http://www.ufrgs.br/edu_realidade> 
Juventude e Participação

Qual não foi nossa surpresa ao percebermos que muitas dessas premissas das entidades convencionais não são apropriadas pelos jovens no grêmio. Ao que parece os jovens tendem a se afastar de práticas que não reflitam suas vivências, assim, tendem a desconsiderar a burocracia (Brasil, 2006; Abad, 2004; Abramo, 2004). Pelo que vimos, a lógica dos jovens tende a não se enquadrar em uma lógica burocratizada, mas as coisas realmente acontecem, mesmo assim. Ou seja, os jovens criaram um ritmo particular, uma dinâmica e organização próprias.

No que se refere às reuniões do grêmio, além do fato de elas ocorrerem no horário escolar, outro aspecto que nos chamou a atenção foi a falta de um cronograma de atividades. Constatamos que a falta do cronograma é proposital e, de acordo com os próprios jovens, com o intuito de ajudar no funcionamento do grêmio, que possui assim uma dinâmica própria, condizente com a lógica vivida por seus membros. O que, para quem está de fora, pode parecer uma total falta de organização, se mostra uma forma de lidar com as dificuldades. A falta de calendário pode ser então entendida como uma estratégia para possibilitar o exercício participativo, uma forma de transpor as dificuldades entre a lógica da escola e a lógica da participação. Possivelmente, sem essa estratégia, as atividades a serem desenvolvidas ocorreriam com maior dificuldade ou nem ocorreriam.

Um ponto chave é perceber que a reunião do grêmio se mostra como um evento importante na vivência desses estudantes. Geralmente, no horário de aula, Karine comenta com seus colegas da mesma sala "temos que resolver o assunto tal, vamos nos reunir hoje, é urgente" (Karine, dezesseis anos). Os membros de outras salas também são chamados. No horário marcado, reúnem-se, principalmente, na biblioteca, mas, se estiver ocupada, reúnem-se onde for possível. Dos dez membros, geralmente, aparece a maioria, somente não vão aqueles que estão ocupados com atividades avaliativas. Já chegam perguntando: qual é o pepino?. Às vezes, parece que se reúnem sempre para resolver problemas. O clima é muito descontraído e, entre os momentos de discussão dos temas levantados, há brincadeiras, piadas e risos. Ao contrário do que se possa esperar de uma reunião de trabalho, a reunião do grêmio não parece ser algo enfadonho.

A forma de atuação dos jovens faz com que uma atividade, que poderia ser maçante, se torne interessante ao grupo. É claro que os momentos não são somente de brincadeira, pode-se perceber isso nas discussões mais sérias, em que o clima se torna mais comedido e os colegas se policiam quanto à conversa paralela e o direito a fazer uso da palavra, bem como, no respeito à fala do outro. Um comenta: "galera, agora é sério, vamos escutar, senão a reunião não anda, como vamos resolver isso?". Durante nosso período de observação (entre março e agosto de 2009), ocorreu uma média de doze reuniões, entre ordinárias e extraordinárias. Pela forma como as coisas aconteceram, consideramos a reunião um momento singular, em que os posicionamentos e discus-

1270 Educação \& Realidade, Porto Alegre, v. 38, n. 4, p. 1267-1282, out./dez. 2013. Disponível em: <http://www.ufrgs.br/edu_realidade> 
sões demonstraram o exercício do respeito à opinião do outro, mesmo não concordando com ela. Em função disso, percebemos tal momento como fomentador de práticas alicerçadas no debate democrático.

Essa prática, das reuniões, incide diretamente nas aulas e atividades escolares, uma vez que algumas atividades são perdidas, mesmo que posteriormente sejam repetidas. Sobre uma atividade perdida na disciplina de inglês, Karine comenta que:

\begin{abstract}
Não, a gente não costuma perder muita atividade não. Quando perde mesmo é quando tem assim uma reunião de grande importância, quando a gente tem que sair assim..., de grande importância mesmo. Igual, essa vez quando a gente perdeu a atividade de inglês, a gente foi lá conversou com a professora e como a maioria das professoras daqui vêem a nossa preocupação, eles assim tornam a repetir numa boa pra gente (Martins, 2010, p. 86).
\end{abstract}

O depoimento da jovem nos sinaliza a existência de duas lógicas, a lógica da participação no grêmio e a lógica dos tempos escolares. A lógica da juventude e a lógica da escola. A estrutura rígida dos tempos, bem como o funcionamento tradicional hierárquico e a centralização do poder são obstáculos enfrentados pelos jovens (Dayrell, 2007). A dissonância entre a cultura educacional e a vivência dos jovens é tamanha que Corti e Souza (2004) vislumbram a ocorrência do desmembramento entre um Mundo Escolar e outro Juvenil. De acordo com as autoras, a distância entre esses mundos e "[...] a consequente dificuldade de comunicação entre os dois, tem gerado um enfraquecimento da capacidade educativa da escola e favorecido uma socialização juvenil incompatível com os princípios éticos e democráticos" (Corti; Souza, 2004, p. 103).

Assim como há uma distância entre o mundo escolar e o mundo juvenil, podemos perceber uma distância entre o mundo da escola e o mundo real no qual os jovens estão inseridos (Dubet, 2006). É importante considerarmos que o jovem não se educa exclusivamente na escola. Ele se forma nos mais variados espaços de convívio social e, com isso, apropria-se de experiências que, muitas vezes, eram cerceadas pela escola ou nem mesmo existiam em tal ambiente. Essas novas aprendizagens, que tendem a não ser reconhecidas como válidas pela instituição escolar, possibilitam a formação de uma identidade multifacetada (Melucci, $2001 ; 2004)$ que suplanta o hermetismo da identidade exclusiva de aluno (Sacristan, 2005).

Nesse sentido, a atuação do jovem em seu processo educacional escolar pode não condizer com o ser aluno idealizado pela instituição. Aos jovens, cabe a tentativa de se adaptar e conviver nesse turbilhão: mundo escolar, mundo juvenil, mundo real. Ônus e bônus, escolhas e responsabilidade em torno das escolhas feitas. Fica claro que a noção de tempo da instituição escolar destoa do tempo da participação dos jovens. Há uma cisão posta. A participação tende a não ser vista pela 
escola como parte do processo de formação. Ao que parece, ela não se apresenta como um tempo válido ao divergir da lógica estrutural dos tempos escolares.

Tal situação, de conflito entre tempos e lógicas diferentes, não é vivida de maneira tranquila por todos os membros do grêmio e influencia no número de participantes nas atividades. Contudo, de acordo com alguns professores, a ocorrência das reuniões nos finais de semana seria a saída mais adequada. Sobre esse tema a professora de inglês comenta:

\begin{abstract}
Primeira coisa, disponibilidade e dedicação. Então é reunir sábado à tarde mesmo, ou é no domingo de manhã. Então assim, você tem que... É doação, é mais até que dedicação, é doação. Se você não tiver com doação voluntária mesmo, para que aquilo aconteça, ficar utilizando horário de aula, "ah, vamos pegar a aula daquele professor chato e tal", serve como válvula de escape. Resolve um problema e arruma outro (Martins, 2010, p. 88).
\end{abstract}

A fala da professora nos aponta que a sua visão em torno da militância, da participação dos jovens e do movimento estudantil ainda parece estar pautada no exemplo dos jovens das décadas de 60 e 70 do século vinte, em que o movimento tendia a ser maior que o indivíduo (Sposito, 2000). Em se tratando dos movimentos sociais nas sociedades contemporâneas, Melucci (2004) nos chama a atenção para as singularidades do momento atual. A realidade nos apresenta uma sociedade global, dinâmica, multiexperimental, em que a quantidade de informações suplanta nossa capacidade de assimilação. Nesse contexto, o subjetivo está posto no cerne das questões do processo de individuação. De acordo com o autor, atuar coletivamente não suprime a subjetividade. O indivíduo, ao atuar coletivamente, lida com suas tensões identitárias, constrói sua consciência e se reconhece dentro dos limites impostos pela sociedade e pelas relações sociais. Segundo Melucci (2004), “[...] não podemos mais identificar nossas necessidades de modo unívoco, pois elas pertencem a um campo simbólico atravessado por tensões" (p. 41).

Diante disso, entre as várias oportunidades e caminhos que se apresentam aos jovens em sua vivência, a opção pela participação no movimento estudantil é mais uma, das quais ele pode optar, inclusive momentaneamente, de acordo com seu interesse. Outras tensões podem perpassar suas questões subjetivas e também mobiliza-lo para atuar em outras vertentes. Devemos perceber que esse jovem pode não ser estudante, exclusivamente. Dentre as outras tensões vividas, podem estar o trabalho, a raça, a sexualidade, a falta de uma moradia, a inexistência de uma área de lazer no bairro, as dificuldades de acesso à universidade, e tantas outras coisas. O que se apresenta como questão premente é exatamente a articulação do interesse subjetivo com as demandas coletivas.

1272 Educação \& Realidade, Porto Alegre, v. 38, n. 4, p. 1267-1282, out./dez. 2013 Disponível em: <http://www.ufrgs.br/edu_realidade> 
Retomando a fala da professora, o que parece, é que, segundo ela, a participação se torna sacerdócio, demanda uma dedicação que muitas vezes não condiz com a realidade dos envolvidos. Os jovens deveriam preterir outras possibilidades que lhes são apresentadas em prol da participação estudantil unicamente? Eles deveriam abrir mão do seu descanso em prol de uma melhor atuação na escola, uma atuação que não atrapalhe nos horários? Mas, e os jovens? O que eles acham disso? A maioria, por trabalhar, utiliza os finais de semana para descanso e diversão. Sobre as reuniões e a possibilidade de se encontrarem nos finais de semana, os jovens são categóricos: o final de semana é sagrado, uma jovem comentou "[...] fica essa confusão pra poder reunir e fora do horário de escola é pior ainda, aí que não dá mesmo” (Andresa, dezesseis anos).

O posicionamento diante desta realidade varia de acordo com os jovens envolvidos. Alguns não veem problema e se saem bem, outros preferem não correr riscos ao perder as atividades e as matérias. A questão é lidar com a dificuldade e se responsabilizar pelas escolhas feitas. Em função disso, há uma grande rotatividade no número de pessoas que compõem o grêmio, quem participava ontem já não participa hoje. A chapa que se iniciou com cerca de vinte pessoas, no momento da observação, ao final contava somente com dez membros.

A rotatividade é uma das dificuldades mencionadas pelos jovens e que afeta a atuação e organização do grêmio. Vários são os motivos de desligamento. Seja por que saiu da escola, por que se formou ou mesmo por que ele simplesmente não quis mais participar. Ao mesmo tempo, a rotatividade é também uma oportunidade de angariar novas forças, e, nesse sentido, há um lado bom. De acordo com Karine:

Teve essa rotatividade, pelo fato assim, da gente ver as pessoas que saíram que não se interessavam pelo grêmio, aí por isso que houve essa mudança, mas de uma certa forma foi bom, porque saíram pessoas desinteressadas e entraram pessoas bem formadas,assim, sabendo o que ia acontecer ali se eles entrassem (Martins, 2010, p. 90).

A jovem nos fala que, assim como a saída de alguns pode prejudicar o grêmio, a chegada de novos membros pode trazer uma energia nova, novas práticas, novas opiniões. Esse é um aspecto da rotatividade. Esse tipo de ocorrência, de momentos de pertencimento e desligamento, de estar junto e depois não estar mais, pode ser visto como um reflexo da sociedade e dos atuais movimentos sociais, que são compostos por pessoas heterogêneas. Os movimentos têm seus conflitos internos e gastam muito de sua energia com sua própria manutenção (Melucci, 1999; 2001). No grêmio, destacamos as divergências de opinião, a disputa de poder, bem como a manutenção do status de determinado cargo, dentre outras coisas. Percebemos, na pesquisa, que essa situação influencia nos rumos tomados pelo grêmio e no êxito de suas atividades.

Educação \& Realidade, Porto Alegre, v. 38, n. 4, p. 1267-1282, out./dez. 2013. 1273 Disponível em: <http://www.ufrgs.br/edu_realidade> 
A questão é que, em um grupo de jovens, reunidos para discutir assuntos de seu interesse, esperar um consenso absoluto das opiniões é no mínimo difícil. Os trabalhos com os quais dialogamos nos mostram que a divergência no interior do grêmio é inerente ao processo participativo vivido pelos jovens (Fernandes, 2001; Moreira, 2001; Carlos, 2006).

A pesquisa evidenciou o que Moreira (2001) também constatou, ou seja, o grêmio se mostra como local privilegiado para a ampliação das relações pessoais, para o companheirismo, para ouvir e respeitar o outro em seus posicionamentos e opiniões. Ao mesmo tempo apresenta uma dimensão educativa muito significativa para os seus membros. Sobre tal tema, Gabriel comenta:

Eu acho que no grêmio você desenvolve bastante seu senso critico mesmo, das coisas, você aprende a dar sua opinião, aprende a ouvir as pessoas assim... as opiniões deles e tentar tipo assim às vezes juntar as coisas para formar uma coisa boa pra todos (Martins, 2010, p. 93).

Para este jovem, a participação no grêmio envolve aspectos importantes no que se refere ao senso crítico, bem como ao aprendizado da escuta, do ouvir o outro e suas considerações e mesmo a busca de um consenso por meio da discussão. Uma educação relacionada à prática, ao fazer, ao se relacionar com os outros. Ainda nessa perspectiva, Rodrigo comenta:

Eu adquiri novas experiências e novos aprendizados com o grêmio, eu aprendi a ser mais responsável com o grêmio, tanto é que quando eu entrei no grêmio eu não tinha uma gota de responsabilidade e com o grêmio eu aprendi a me... a lidar mais com as pessoas, a ser mais compreensível e mais compassível e eu acho que isso vai me ajudar muito na minha vida, no dia a dia (Martins, 2010, p. 93).

A fala do jovem é marcada pelo destaque dado aos aprendizados para a vida, a responsabilidade e a busca pela compreensão do ponto de vista do outro. Nesse sentido, ele demonstra consciência da importância dessa participação ao chamar a atenção para o caráter formativo contido nas experiências proporcionadas pelas atividades do grêmio.

É importante ressaltar também esse momento de atuação, como um momento de discussão e elaboração de propostas quanto aos objetivos a serem alcançados, além de articulação dos membros ao defender e argumentar sobre suas ideias, Andresa comenta:

É por causa que assim quando a gente fala assim, "ô, vamos fazer isso", aí o outro pra ele se engrandecer dentro do grêmio fala, "não, não, é melhor fazer isso, não é melhor fazer isso". Assim essa disputa acaba atrapalhando muito, porque acaba não fazendo nem um nem o outro (Martins, 2010, p. 94). 
Há uma disputa em que a capacidade de argumentação é ponto chave; contudo, pode, às vezes, servir de embargo ao desenvolvimento das atividades. A oportunidade de se colocar, de defender posições e sofrer oposição é um ponto central da capacidade educativa contida no processo de conflito. Há ainda um importante caráter prático contido nessas atividades, diferenciando-se da discussão teórica simplesmente. Conforme nos mostra Rodrigo, esse é um momento de:

Colocar tudo que... tudo em prática, aquilo que ele aprendeu e aquilo que ele quer aprender, porque não basta você ficar lá na decoreba o ano inteiro e chega no final do ano você não sabe nada, você tenta decorar tudo o ano inteiro e quando chega no final do ano cadê? Não aprendeu nada (Martins, 2010, p. 94).

O que se percebe é que os jovens reconhecem a importância das atividades participativas como exercício prático, que ultrapassa os aprendizados unicamente teóricos, sem desconsiderar a importância da teoria, se for adequadamente apropriada. Tais experiências, muitas vezes ausentes na escola, tendem a enriquecer o processo formativo educacional dos jovens para além do estritamente conceitual (Santos, 1996). Dialogando com Boaventura, percebemos que:

\begin{abstract}
Um projeto educativo emancipatório tem de colocar o conflito cultural no centro do seu currículo. As dificuldades para o fazer são enormes, não só devido a resistência e a inércia dos mapas culturais dominantes, mas também devido ao modo caótico como os conflitos culturais têm vindo a ser discutidos no nosso tempo (Santos, 1996, p. 29).
\end{abstract}

Entendemos que o aprendizado é intrínseco ao processo de conflito, argumentação e escuta do outro. O digladio de forças, a disputa e o conflito aparecem de forma recorrente nas falas dos jovens. O que nos parece importante é entendermos que tudo isso está ligado a um processo de ação educativa que pode proporcionar um rico aprendizado no lidar com o próximo, com outras pessoas de direitos, e, consequentemente, respeitar e reconhecer essas diferenças.

\title{
As Relacões entre os Jovens do Grêmio e os Estudantes da Escola: a questão da representação
}

Em matéria de articulação entre os jovens do grêmio e demais estudantes da escola, há que se considerar questões importantes. O contato com os jovens da escola em sua totalidade, em uma espécie de assembleia, é algo difícil de articular de acordo com os membros do grêmio. Durante a observação, não houve a ocorrência de nenhuma assembleia. De acordo com os jovens, isso ocorre em função de questões estruturais, espaço, disponibilidade de tempo por parte da escola. Diante disso, é utilizada uma ferramenta: a promoção de reuniões com

Educação \& Realidade, Porto Alegre, v. 38, n. 4, p. 1267-1282, out./dez. 2013. 1275 Disponível em: <http://www.ufrgs.br/edu_realidade> 
os representantes de turma. Nessas reuniões, os problemas, as questões e demandas são passadas aos representantes para serem repassadas aos estudantes em sala.

Na escola, a eleição dos representantes de turma se apresenta como um importante exercício participativo por parte dos jovens estudantes, apesar dos seus limites. É uma oportunidade de escolha efetiva. De acordo com os jovens entrevistados na pesquisa, a eleição dos representantes acontece em sala com o auxílio das pedagogas. É feita em voto aberto e os jovens se candidatam na hora, o que privilegia a eleição dos alunos tidos como populares e bagunceiros.

Todavia, na escola estudada, o grande problema está na atitude de alguns representantes de turma que, de acordo com os membros do grêmio, não repassam as informações ou nem mesmo comentam da ocorrência de tal reunião. Em se tratando das reuniões com os representantes de turma, essas são marcadas da mesma forma que as reuniões do grêmio, em função das demandas. Não há uma periodicidade preestabelecida e uma antecedência de comunicação que possa garantir aos representantes sua organização e presença. Daí, o comparecimento maciço dos representantes ser muito difícil. No período da pesquisa, aconteceram entre cinco a seis reuniões desse tipo, com o comparecimento de uma média de dez representantes, em um universo de quatorze salas.

Em uma das reuniões, para tratar de comunicações em torno de algumas mudanças pretendidas pela prefeitura junto à Fundação ${ }^{2}$, os jovens fizeram o comunicado das informações que eles tinham, propuseram um plano de ações para um evento contra tais mudanças. Em linhas gerais, alguns dos representantes se envolveram com a reunião, discutiram propostas com os membros do grêmio e apresentaram o posicionamento da sala. Nessa reunião, alguns questionaram a posição do grêmio, salientando: “[...] vocês são sempre do contra! Por que em vez disso não tão mexendo com um campeonato de futebol? Tem coisas que não adianta a gente mexer, se eles (Prefeitura) quiserem acabar com a Fundação eles acabam e pronto!" (Trecho de depoimento - Diário de Campo, 2009). Outros se posicionaram a favor das atitudes do grêmio e se propuseram a ajudar, se responsabilizaram por algumas atividades e se comprometeram em divulgar para a escola e para a comunidade.

Os posicionamentos diferentes em torno das propostas do grêmio nos evidenciam que nem tudo o que os jovens da agremiação propõem tem aceitação unânime. Na referida reunião, os jovens do grêmio tiveram de defender seu posicionamento a todo instante, para validar suas atitudes e, também, o próprio grêmio. Os jovens tentam explicar qual a função do grêmio que, ao representar os estudantes, deve, também, defender a manutenção da Fundação. Apesar do bom relacionamento do grêmio com o coletivo de estudantes, nem todos reconhecem a instituição estudantil como algo importante na escola.

1276 Educação \& Realidade, Porto Alegre, v. 38, n. 4, p. 1267-1282, out./dez. 2013 Disponível em: <http://www.ufrgs.br/edu_realidade> 
De acordo com os jovens do grêmio, as atitudes dos representantes de turma, de faltar às reuniões e de não repassar os assuntos para a sala poderiam dificultar a representação da sala junto ao grêmio e junto à própria escola. Se essas demandas e discussões não chegam à sala, cria-se a falsa aparência que o grêmio está inerte. Dessa situação, decorre uma tensão entre os estudantes e os membros do grêmio. Segundo os jovens gremistas, se o representante de turma não abraçar a ideia, não repassar as atividades, não fizer as comunicações em sala, pode parecer, ao coletivo de estudantes, que nada está sendo feito, que o grêmio não faz nada na escola.

Essa situação está intimamente ligada à representação e às tensões inerentes a ela, o que aponta para o debate em torno do caráter da representação. De acordo com Norberto Bobbio, a representação evoca uma multiplicidade de significados destacando-se: "[...] substituir; agir no lugar de ou em nome de alguém ou de alguma coisa; evocar simbolicamente alguém ou alguma coisa; personificar" (Bobbio, 2000, p. 1102).

A representação apresenta-se como uma complexa rede institucional que pode ser vista como processo de competição e disputa ininterrupta. Em função disso, envolve responsabilidade que "[...] quer dizer chamado para responder, para prestar contas, das próprias ações junto daqueles que têm o poder da designação" (Bobbio, 2000, p. 1105). Uma questão importante está no controle do poder atribuído a quem não pode exercer pessoalmente, daí a existência de uma tensão advinda da diversidade entre representantes e representados. Segundo Melucci (2001), “[...] a representação implica uma distância inevitável entre representantes e representados, entre interesses de uns e de outros, entre lógicas da ação que podem concorrer, mas também divergir" (p. 130). Por mais que se esforce, o representante fica impossibilitado de atender os anseios de seus representados em sua totalidade. Contudo, Melucci (2001) destaca que a diminuição da distância entre as estruturas de representação e as demandas e interesses pode ser um caminho.

Sobre a cobrança dos estudantes e o não reconhecimento do trabalho do grêmio, Nayara ressalta "[...] eles não têm noção de como o grêmio trabalha” (Martins, 2010, p. 100). Tal fala nos sinaliza que a distância também pode estar ligada à falta de conhecimento dos representados quanto aos trâmites burocráticos enfrentados pelos representantes. Muitas vezes, os jovens do grêmio são interpelados pela estrutura funcional da escola, o que inviabiliza que as coisas sejam feitas simplesmente como eles acham que podem e devem. Em contrapartida aos posicionamentos dos estudantes, em relação ao grêmio, seus membros e sua atuação na escola, os jovens do grêmio tendem a considerar alguns dos estudantes acomodados, indispostos a sair da sala para se mobilizar ou discutir as coisas referentes à escola. Rodrigo faz as seguintes considerações “[...] interessar eles interessam, só que eles interessam lá dentro da sala de aula" (Martins, 2010, p. 100).

Educação \& Realidade, Porto Alegre, v. 38, n. 4, p. 1267-1282, out./dez. 2013

Disponível em: <http://www.ufrgs.br/edu_realidade> 
Tal consideração pode inclusive servir aos jovens do grêmio como proteção ou retaliação contra as críticas. Remetemos-nos aos papéis vivenciados por esses jovens, pertencentes e não pertencentes ao grêmio. O que nos salta aos olhos é a culpa imputada ao outro, por ambos os campos. Fica a questão: Isso não seria algo comum a outras instituições? A culpa recíproca estaria relacionada aos papéis e aos lugares ocupados pelos envolvidos? Essa situação estaria ligada à forma de vivenciar os papéis?

Pode parecer que os jovens do grêmio, simplesmente, culpam o outro, como forma de se isentar da responsabilidade. O que percebemos é que os jovens se esforçam para fazer as coisas acontecerem dentro da escola, porém, entre o esforço do grêmio e as coisas acontecerem como os demais estudantes acham que devam acontecer, há uma distância considerável. Assim como, há uma distância entre fazer e agradar há também, uma distância enorme entre fazer e ser reconhecido pelo que foi feito.

Por outro lado, torna-se perceptível que os problemas vividos entre os jovens e alguns estudantes suplantam simplesmente as questões referentes à comunicação e cobrança. Ser membro do grêmio dá destaque àquele que ocupa tal cargo, há um status inerente à função. São jovens que são convocados para reuniões, que têm permissão para sair da sala rotineiramente, que estabelecem discussões, argumentam e defendem seu ponto de vista. Os jovens do grêmio ressaltam que muitos estudantes os consideram "metidos", como se fossem intelectuais, aqueles que acham que sabem tudo. Andresa ao tratar de tal tema, comenta: "[...] posso falar que assim os estudantes daqui da escola, eles veem assim o grêmio como pessoas que querem ser superiores" (Andresa, dezesseis anos).

A atuação no grêmio está ligada ao exercício do poder de representar os estudantes. Juntamente a essa atuação, advêm as consequências desse exercício participativo. Ser detentor de poder pressupõe responsabilidade em seu exercício e, consequentemente, a obrigação de prestar contas e responder por seus atos. O que fica explícito é que a relação estabelecida entre o grêmio e os estudantes é perpassada por questões particulares referentes à atuação e ao reconhecimento dessa atuação. Essas relações demonstram que o processo de organização, funcionamento e comunicação do grêmio, para com o estudante, é singular. É reflexo dos acontecimentos e experiências vividas no cotidiano da escola. Em se tratando de convivência, da atuação em um coletivo, o conflito assume papel central no processo relacional. No cotidiano escolar, no processo de construção dos aprendizados, as situações de conflito se apresentam como oportunidades singulares para discussão e defesa de posições. Nesse contexto, ao contrário do que ecoa no senso comum, o conflito se mostra mais frutífero que o consenso.

1278 Educação \& Realidade, Porto Alegre, v. 38, n. 4, p. 1267-1282, out./dez. 2013 Disponível em: <http://www.ufrgs.br/edu_realidade> 


\section{As Tensões Vividas no Interior do Grêmio: os jovens se relacionando entre si}

Para além da relação com o coletivo de estudantes, a organização do grêmio é perpassada por conflitos e disputas internas. Essa situação pode ser entendida como decorrente da organização e atuação dos movimentos sociais na sociedade contemporânea, bem como, da diversidade dos atores que os compõem. O movimento, se percebido simplesmente como uma unidade em si, dotado de uma harmonia inata, pode turvar nossa visão para perceber suas relações interiores. Assim, o esforço está em perceber o movimento social, e consequentemente, o movimento estudantil, como uma teia complexa de relações e disputas a serem estabelecidas em seu interior. Nesse aspecto, a perenidade do movimento demanda um grande dispêndio de energia para com suas questões internas, negociações, conflitos e decisões (Melucci, 1989; 1999; 2001).

Nesse contexto, a participação no grêmio estudantil envolve posicionamentos e práticas que refletem uma Identidade Coletiva como um sistema de ação desenvolvido pelo grupo. Essa identidade também se envolve em negociações e conflitos. A atuação do movimento decorre da formação de um NÓS que envolve solidariedade entre seus membros (Melucci, 2001). Ou seja, uma identificação, algo comum, que dá sentido às ações. Em função disso, os próprios jovens do grêmio estabelecem posturas e se cobram entre si, assim como são cobrados pelos demais estudantes. Essas cobranças foram responsáveis por momentos de tensão e ruptura na gestão estudada.

Um dos pontos de tensão girava em torno da atuação do presidente Rodrigo que era muito criticada por parte de alguns componentes do grêmio, dizendo que ele faltava muito às aulas, que faltava às reuniões e compromissos do grêmio. Alguns membros cobravam postura do presidente e o acusavam de provocar a desunião do grêmio. Diante disso, percebemos disputas em torno de posicionamentos, consequentemente, divergências. Em função dessas disputas, nos momentos de maior inflamação, alguns membros pensavam até que o grêmio fosse acabar! Karine comenta que "já teve momento que eu achei que o grêmio ia se diluir, que ia se separar mesmo, que ia cada um pro seu canto e que esquecesse o grêmio" (Karine, dezesseis anos).

Em contraposição ao que os jovens do grêmio comentam, Rodrigo se defendeu e justificou suas faltas. Contudo, um episódio em que ocorreu a disputa por uma cadeira no colegiado, na qual Rodrigo foi preterido, acabou por servir de motivo ao seu afastamento e rompimento com o grêmio. O calor da disputa nos sinaliza que de um lado se coloca o arroubo e a incisão dos jovens em defender suas posições, e do outro, coloca-se a necessidade de se adaptar e se posicionar nas instâncias de atuação e exercício de poder. Cremos que muito disso, pode ser reflexo da condição juvenil vivida pelos envolvidos, da maneira de ser e situarse perante as experiências da vida (Leite; Hermont, 2009).

Educação \& Realidade, Porto Alegre, v. 38, n. 4, p. 1267-1282, out./dez. 2013.

Disponível em: <http://www.ufrgs.br/edu_realidade> 
Juventude e Participação

Em linhas gerais, o grêmio acabou ficando sem um presidente. Os jovens optaram por não fazer uma eleição interna. O mandato da atual chapa já estava chegando ao final e, de acordo com eles, não haveria por que eleger alguém somente para entregar o bastão à próxima chapa.

\section{Considerações Finais}

Em se tratando dos jovens e as experiências proporcionadas pela participação no grêmio estudantil, mesmo com as dificuldades inerentes ao processo participativo, há que se ressaltar que, na escola estudada, o grêmio se apresentou como um espaço educativo, para além da sala de aula, com um potencial formativo intimamente ligado ao fazer, à prática. Além disso, percebemos que a existência dessa instituição no interior da escola pode trazer algo novo, diversificar a representatividade no cotidiano da escola, permitir aos jovens a ocupação de outros lugares para além da sala de aula e do papel exclusivamente de aluno.

Em relação à forma de organização do grêmio, percebe-se que essa é singular, que responde às necessidades dos jovens. O que parece uma desorganização para o adulto, pode ser uma estratégia de participação para o jovem que divide seu tempo com a escola, o trabalho e o lazer. A organização desorganizada foi uma das saídas para jovens que vivem a condição juvenil em múltiplos papéis, inclusive como militante estudantil. Tais situações nos levam a pensar sobre o interesse dos jovens pelas questões participativas. $\mathrm{O}$ ato de participar não se dá facilmente, eles têm de se esforçar, se adaptar, de abrir mão de espaços e de tempos. Eles optam por participar e isso envolve perdas e ganhos. Essa é uma oportunidade de escolha, e mais do que isso, de se responsabilizar pelas escolhas.

Em se tratando das relações entre os jovens gremistas, observa-se que o grêmio é, também, um local de encontro, de conversa. Contudo, a participação nesse processo não acontece de maneira tranquila. Há que negociar, se posicionar, defender seu ponto de vista. No interior do grêmio, há também algo em jogo, uma posição, um lugar determinado, um status. Uns são mais próximos, outros mais distantes. Esse processo tem a capacidade de fazer com que o jovem perceba que pode não estar sempre certo e, mais do que isso, que tem de articular seus pensamentos de forma a ser entendido pelo grupo, sob o risco de prevalecer o posicionamento de outro colega com o qual está em disputa. Esse é um tipo de experiência que pode preparar o jovem para a vida.

Sobre a relação estabelecida entre os jovens gremistas e os demais estudantes da escola, percebeu-se que ela não é tão simples. Por serem representantes dos estudantes, pode parecer que o reconhecimento seja quase que automático, porém, o fenômeno é bem mais complexo. Ao adentrarem para o grêmio, os estudantes têm de lidar com uma cobrança ininterrupta por parte daqueles aos quais representam. Essa situação se difere totalmente da representação política no aspecto da

1280 Educação \& Realidade, Porto Alegre, v. 38, n. 4, p. 1267-1282, out./dez. 2013. Disponível em: <http://www.ufrgs.br/edu_realidade> 
presença do representado, fiscalizando o representante diuturnamente no exercício da função. Nesse aspecto, a todo instante, os jovens têm de provar sua capacidade, buscar o reconhecimento. A margem de erro é muito pequena e a preocupação com o fazer a coisa certa, uma constante. Ser membro do grêmio, também, significa se responsabilizar pelo sucesso ou fracasso das atividades. Essas são situações praticamente impossíveis de se ensinar na sala com quadro e giz; isso só se aprende ao fazer.

No que diz respeito às experiências participativas, tanto ocorridas na escola quanto fora da escola, é indubitável seu caráter educativo. Nesse aspecto, os próprios estudantes ressaltaram que tais aprendizados ultrapassam a teoria. Nesses momentos, os jovens gozam de uma autonomia maior, de liberdade, eles experimentam o caminhar sem tutela. Tais situações não pressupõem uma exacerbação da liberdade, contudo, criam espaços e situações que podem funcionar como formação pela experimentação, pelo acertar e errar.

Recebido em 08 de maio de 2012 Aprovado em 08 de outubro de 2013

\section{Notas}

1 Os nomes da escola e do bairro foram omitidos para a manutenção da privacidade da instituição. Em se tratando dos sujeitos entrevistados, foram utilizados nomes fictícios. Tal prática caminha no sentido de obedecer aos procedimentos éticos estabelecidos pelo Comitê de Ética em Pesquisa da Universidade em que se desenvolveu a pesquisa.

2 A prefeitura tinha a intenção de diminuir as unidades da fundação, dentre as quais a unidade do bairro estudado.

\section{Referências}

ABAD, Miguel. Possibilidades e Limites da Participação Juvenil para o Impacto na Agenda Pública. Recife: Projeto Redes de Juventude, 2004.

ABRAMO, Helena. Participação e Organizações Juvenis. Recife: Projeto Redes de Juventude, 2004.

BOBBIO, Norberto et al . Dicionário de Política. Brasília: Editora UNB, 2000.

BRASIL. Instituto Brasileiro de Análises Sociais e Econômicas - IBASE. Juventude Brasileira e Democracia: participação, esferas e políticas públicas. Relatório Global. Rio de janeiro: IBASE, jan. 2006.

CARLOS, Aparecida da Graça. Grêmio Estudantil e Participação do Estudante. 2006. Dissertação (Mestrado em Educação) - Programa de Pós-Graduação em Educação, Faculdade de Educação, Pontifícia Universidade Católica de São Paulo (PUC-SP), São Paulo, São Paulo, 2006.

CORTI, Ana Paula; SOUZA, Raquel. Diálogos com o Mundo Juvenil: subsídios para educadores. São Paulo: Ação Educativa, 2004.

Educação \& Realidade, Porto Alegre, v. 38, n. 4, p. 1267-1282, out./dez. 2013. 
DAYRELL, Juarez. A Escola $f a z$ as juventudes? Reflexões em torno da socialização juvenil. Revista Educação e Sociedade, Campinas, v. 28, n. 100, p. 1105-1128, 2007.

DUBET, François. El Declive de la Instituición: profissiones, sujetos e indivíduos ante la reforma Del Estado. Barcelona: Gedisa, 2006.

FERNANDES, Manuel José Pina. Entre o Sindicato e o Grêmio: como se organiza o trabalhador-aluno. 2007. Dissertação (Mestrado em Educação Brasileira) - Programa de Pós-Graduação em Educação Brasileira, Faculdade de Educação, Universidade Federal do Ceará (UFCE), Recife, Ceará, 2007.

LEITE, Lucia Helena Alvarez; HERMONT, Catherine. Ser Jovem e Ser Aluno. In: SOARES, Leôncio; SILVA, Isabel de Oliveira. Sujeitos da Educação e Processos de Sociabilidade: os sentidos da experiência. Belo Horizonte: Autêntica, 2009. P. 219-236.

MARTINS, Francisco André Silva. "A Voz do Estudante na Educação Pública: um estudo sobre participação de jovens por meio do grêmio estudantil". 2010. Dissertação (Mestrado em Educação) - Faculdade de Educação da Universidade Federal de Minas Gerais (UFMG), 2010.

MELUCCI, Alberto. Um Objetivo para os Movimentos Sociais? Lua Nova: Revista de Cultura e Política, São Paulo, n. 17, p. 49-66, jun. 1989.

MELUCCI, Alberto. Acción Colectiva, Vida Cotidiana y Democracia. Pedregal de Santa Tereza: Centro de Estudos Sociológicos, 1999.

MELUCCI, Alberto. A Invenção do Presente. Petrópolis: Vozes, 2001.

MELUCCI, Alberto. O Jogo do Eu. São Leopoldo: Unisinos, 2004.

MOREIRA, Marco Antônio. Grêmios Estudantis: contestação e distinção social. Rio de Janeiro: Papel Virtual, 2001.

SACRISTAN, José Gimeno. O Aluno como Invenção. Porto Alegre: Artmed Editora, 2005.

SANTOS, Boaventura de Sousa. Novos Mapas Culturais, Novas Perspectivas Educacionais. Porto Alegre: Sulina, 1996.

SPOSITO, Marília Pontes. Algumas Hipóteses sobre as Relações entre Movimentos Sociais, Juventude e Educação. Revista Brasileira de Educação, São Paulo, ANPED, n. 13, p. 73-94, 2000.

Francisco André Silva Martins é graduado em História (Licenciatura Plena), Especialização (Pós-Graduação Lato Sensu) História e Cultura de Minas Gerais, Curso de Aperfeiçoamento em História da África, Mestrado em Educação e Doutorado em andamento em Educação. Membro do Observatório da Juventude - Faculdade de Educação - UFMG, em Belo Horizonte, no estado de Minas Gerais.

E-mail: fasm.historia@yahoo.com.br

Juarez Tarcísio Dayrell é doutor em Educação. Professor Adjunto da Faculdade de Educação na UFMG, Coordenador do Observatório da Juventude em Belo Horizonte, no estado de Minas Gerais.

E-mail: juareztd@uol.com.br

1282 Educação \& Realidade, Porto Alegre, v. 38, n. 4, p. 1267-1282, out./dez. 2013. Disponível em: <http://www.ufrgs.br/edu_realidade> 